Revista Monografias Ambientais

Santa Maria, Santa Maria, Edição Especial Curso de Especialização

em Educação Ambiental. 2015, p. 117-119

Revista do Centro de Ciências Naturais e Exatas - UFSM

ISSN : 22361308

\title{
Vamos Cuidar do Brasil - O Desafio da Educação Ambiental nas Séries Finais do Ensino
} Fundamental

\author{
Let's Take Care of Brazil - The Challenge of Environmental Education In Series Final Elementary
}

School

\author{
Eliana Aparecida Cadoná ${ }^{1}$; Luciane Sippert²; Divanilde Guerra ${ }^{3}$; Robson Evaldo Gehlen Bohrer ${ }^{4}$; \\ Mastrângello Enivar Lanzanova ${ }^{5}$ \\ ${ }^{1}$ Especialista, Três Passos, UERGS, Três Passos, RS, Brasil; ${ }^{2}$ Mestre, São Luiz Gonzaga, UERGS, Três Passos, RS, Brasil; \\ ${ }^{3}$ Doutor, Três Passos, UERGS, Três Passos, RS, Brasil; ${ }^{4}$ Mestre, Três Passos, UERGS, Três Passos, RS, Brasil; \\ ${ }^{5}$ Doutor, Três Passos, UERGS, Três Passos, RS, Brasil.
}

\section{Resumo}

A Educação Ambiental é, na atualidade, o maior desafio das escolas e de seus professores, pois, a cada dia que passa, inúmeras discussões surgem em torno desta temática. É perceptível a necessidade desta inserção, pois as mudanças climáticas e ambientais que estamos presenciando são atribuídas, quase que de forma exclusiva, à ação antrópica. $\mathrm{O}$ presente trabalho tem como objetivo avaliar e apresentar um relato da experiência de trabalho realizada com uma turma de alunos das séries finais do Ensino Fundamental acerca da problemática do ambientalmente correto, utilizando, como ferramenta, o material didático disponível pelo governo federal. Trata-se de uma pesquisa-ação. Os resultados preliminares demonstram algumas mudanças observadas com relação ao uso da água com maior racionalidade, à necessidade de sensibilizar aos pais acerca do uso irracional de agrotóxicos e à utilização da água para a veiculação destes produtos, sobre a necessidade de manutenção e ampliação das matas. Conclui-se, assim, que este material tem sido significativo para a iniciação da Educação Ambiental, tem proporcionado grandes momentos de interação e de reflexão, além de apresentar diferentes maneiras de ensinar os conteúdos propostos, fazendo com que os alunos sejam os sujeitos ativos da construção de sua aprendizagem.

Palavras-chave: Educação Básica, poluição, recursos naturais.

\begin{abstract}
Environmental education is at present the major challenge of schools and their teachers, because every day numerous discussions arise around this issue. The need is noticeable this insertion, as indeed the climate and environmental changes we are witnessing is attributed almost exclusively to human action. This study aims to evaluate and present an account of work experience undertaken with a group of students of final grades of elementary school about the environmentally correct problems, using as a tool, the teaching material available by federal government. This is an action research. Preliminary results show some changes in relation to the use of water with greater rationality, the need to promote the interest of parents about the irrational use of pesticides and the use of water for the placement of these products on the need for maintenance and expansion of forests. It can be seen therefore that this material has been significant for the initiation of environmental education, has provided great moments of interaction and reflection, and present different ways to teach the proposed content, making, students are the active subjects the construction of their learning.
\end{abstract}

Key-words: Basic Education. Pollution. Natural Resources. 


\title{
1 Introdução
}

A Educação Ambiental é na atualidade o maior desafio das escolas e de seus professores, pois a cada dia que passa reconhece-se cada vez mais a importância de inserir esta discussão nos currículos escolares. "A trama do meio ambiente é a trama da própria vida, ali onde se encontram natureza e cultura; o meio ambiente é o cantinho em que se forjam nossa identidade, nossas relações com os outros, nosso "ser-no-mundo" (SAUVÉ, 2005, p. 317). É perceptível a necessidade desta inserção, pois as deveras mudanças climáticas e ambientais que estamos presenciando é atribuído quase que de forma exclusiva a ação antrópica. Dentro deste contexto, diversas discussões surgem de como incluir este assunto tão necessário, ao currículo escolar, como iniciar mudanças de paradigmas e ações, cada vez mais cedo em nossas crianças.

\begin{abstract}
A educação ambiental visa a induzir dinâmicas sociais, de início na comunidade local e, posteriormente, em redes mais amplas de solidariedade, promovendo a abordagem colaborativa e crítica das realidades socioambientais e uma compreensão autônoma e criativa dos problemas que se apresentam e das soluções possíveis para eles (SAUVÉ, 2005, p.317).
\end{abstract}

Dentre deste contexto, o governo federal elaborou propostas de escolas sustentáveis, que consigam fazer com que esta problemática seja a mola-mestre de seus currículos. Dentro deste projeto foram encaminhados às escolas e aos professores um material composto por vários textos, cinco livros, cinco cd-rooms e material lúdico, para que se faça a inserção deste assunto nas escolas, com maior ênfase. Cada livro apresenta uma problemática específica, sendo: I- água no planeta, II- terra/solos no planeta, III - ar no planeta, IV - fogo no planeta, e o último texto, trazia coletâneas de textos, sobre medidas a serem adotadas e trabalhadas na escola, e posteriormente nas famílias, em relação a separação e destinação do lixo, do esgoto doméstico e industrial. Em conjunto com cada livro, existia um cd-room, que apresentava materiais lúdicos e interativos sobre a problemática em questão de cada livro. Os textos que acompanham a coleção, em geral, apresentam-se como poesias e versos, acerca da reflexão que muitos autores já realizaram, e que se apresentam de maneira poética, grandes problemas da humanidade. O material lúdico era composto por atividades reflexivas acerca do uso da água, do solo, da poluição do ar, do manejo dos dejetos humanos e animais. Neste contexto, o objetivo deste trabalho é avaliar e apresentar um relato da experiência de trabalho realizada com uma turma de alunos das séries finais do Ensino Fundamental acerca da problemática do ambientalmente correto, utilizando como ferramenta, o material didático disponível pelo governo federal.

\section{Metodologia}

A metodologia deste trabalho caracteriza-se como uma pesquisa-ação. As atividades foram realizadas com uma turma de $6^{\circ}$ ano, das séries finais do Ensino Fundamental, em uma escola da Educação Básica no município de Esperança do Sul/Rio Grande do Sul, utilizou-se da questão-chave a problemática do ambientalmente correto, utilizando como ferramenta, o material didático disponível pelo governo federal. O período de desenvolvimento deste trabalho foi compreendido entre os meses de agosto a novembro de 2014. A turma era composta por 12 alunos, sendo em sua maioria provenientes do interior do município, sendo desenvolvidas atividades nas aulas de Português, Matemática e Ciências. Priorizou-se a 
construção de textos, a compreensão dos diversos processos textuais que compunham a coletânea.

\section{Resultados e discussão}

Para fazer a utilização do material encaminhado para a escola, inicialmente proporcionou-se aos alunos desenhos à mão livre, de como os mesmos imaginavam que era o local de sua moradia, de sua escola e de seu município quando os primeiros colonizadores chegaram e como eles imaginam o seu meio ambiente daqui a 50 anos, em aulas do componente curricular Ciências. Após a apresentação das figuras, cada um explicava o motivo de colocar aqueles elementos nos desenhos. Para encerrar a discussão do processo imaginativo dos mesmos, trabalhou-se com poemas, que tratam da necessidade da preservação deste meio ambiente que desfrutamos, pois dentro do cenário atual de destruição, não tão distante não teremos mais diversos benefícios dos quais atualmente dispomos. Após a leitura do material bibliográfico indicado, cada aluno apresentou o que compreendeu do mesmo e o que ele acredita que pode modificar em seu cotidiano para melhorar o meio em que vivemos, socialização esta realizada num momento de interação entre os componentes curriculares de Ciências e Português, com destaque para a importância da interdisciplinaridade.

Prosseguindo na discussão proposta, analisou-se o que seriam recursos naturais e de que forma eles estão divididos no município, sendo que, ocorrem opiniões diversas de como cada pessoa consome os recursos naturais e polui o ambiente em que vive. Alguns apresentaram que, quem habita o interior do município, consome alimentos mais saudáveis e que na cidade tudo vem com mais veneno (agrodefensivos), mas em comparação é no interior que os agricultores utilizam veneno (agrodefensivos). Assim, cada um listou o que poderia ser modificado na sua realidade.

Quando se iniciou a discussão da problemática da água, observando aonde se encontravam os principais rios do município e de qual local era proveniente a água que os alunos consumiam na escola e em casa, trabalhou-se a produção textual, a partir de conversas dos mesmos com os familiares, sobre a temática em questão. Observou-se que, a rede de abastecimento de água do município, ocorre por poços artesianos, e que os mesmos, na sua maioria estão em locais poluídos. Os alunos observaram que a água compõe um ciclo na natureza, pois vários anos ocorreram enchentes e logo depois ocorriam estiagens que faziam a maioria dos rios, diminuírem de vazão, e até secar. Concluíram também que a água pode ser um recurso finito no ambiente, como refletido por Resende (2002, p.10): "Ao analisar a distribuição da água no planeta, com base nas estimativas bastante genéricas, chega-se à conclusão preocupante de que se trata de um recurso natural esgotável (não renovável) e muito mais escasso do que se pode imaginar".

Passando da problemática da água, discutiu-se como o ar que nos rodeia pode ser poluído e quais os problemas para o meio ambiente e para as pessoas. Alguns observaram que em dias que "se passa veneno e tem vento", esse atinge superfícies maiores, chegando às vezes nas casas, nos pomares e hortas, pegando nos "bichinhos" fazendo-os adoecer e até morrer. Quando esse veneno é passado próximo às casas, os alunos relataram que logo sentem o cheiro forte do mesmo, o qual causa mau estar, e que em quase todas as famílias alguém já intoxicou-se com esses produtos, seja contaminação por inalação ou contato na pele. Concluiu-se assim, que o ar é algo em constante movimentação no planeta, que o que se joga no ar a quilômetros de distância pode nos atingir e causar doenças. Indo assim, observou-se que as queimadas, que muitos realizam para queimar o lixo ou "mato seco" também pode ir para longe, pois o vento espalha a fumaça, e por vezes, o fogo também, causando danos ao solo, as pessoas, as plantas e ao ar.

Observa-se a necessidade de um trabalho contínuo sobre esse assunto dentro das escolas de maneira inter-relacionada com os conteúdos, ditos escolares, por meio de atividades interdisciplinares, levando em conta a realidade de cada sujeito envolvido no 
processo educativo. Ainda se discute este trabalho, pois o mesmo é construído diariamente, com o intuito de atingir os alunos e empolgá-los acerca dessa discussão e da proposta e ação de mudanças, para conseguirmos melhorar o ambiente que estamos vivendo.

\section{Considerações Finais}

O objetivo deste trabalho foi avaliar e apresentar um relato da experiência de trabalho realizada com uma turma de alunos das séries finais do Ensino Fundamental acerca da problemática do ambientalmente correto, utilizando como ferramenta, o material didático disponível pelo governo federal. O referido material utilizado para a iniciação da educação ambiental proporcionou momentos significativos de interação e de reflexão, além de apresentar diferentes maneiras de ensinar os conteúdos propostos, fazendo com que os alunos sintam-se sujeitos ativos na construção de sua aprendizagem. Nesse sentido, constatou-se durante o período de desenvolvimento deste trabalho, que algumas mudanças puderam ser observadas, tais como: a realização de atividades interdisciplinares envolvendo disciplinas de diferentes áreas do conhecimento; os alunos passaram a utilizar a água com maior racionalidade; conversam com seus pais e familiares acerca do uso irracional de agrotóxicos e a utilização da água para a veiculação destes produtos, bem como sobre a necessidade de manutenção e ampliação das matas e a separação correta do lixo.

\section{Agradecimentos}

Aos professores de Matemática e Português, pelo envolvimento no projeto e cedência de espaço em suas aulas, para que essa temática fosse trabalhada de maneira interdisciplinar.

\section{Referências}

RESENDE, Á. V. de. Agricultura e qualidade da água: contaminação da água por nitrato. Documentos Embrapa Cerrados, Planaltina, DF: Embrapa Cerrados, 2002, 29 p.

SAUVÉ, L. Educação Ambiental: possibilidades e limitações. Educação e Pesquisa, São Paulo, v.31, n.2, p.317-322, maio/ago, 2005. 